\title{
Correction to: Reply to "Complications in DIEP Flap Breast Reconstruction After Mastectomy for Breast Cancer: A Prospective Cohort Study Comparing Unilateral Versus Bilateral Reconstructions"
}

Ryckie G. Wade, MBBS, MClinEd, PGCertHR, MRCS, FHEA ${ }^{1,2}$, Sergio Razzano, MD (Hons) ${ }^{3}$, Elaine M. Sassoon, AB, FRCS (Plast) ${ }^{3}$, Richard M. Haywood, MBBS, FRCS (Plast) ${ }^{3}$, Justin C. R. Wormald, MBBS (Hons), MRes (Hons), MRCS ${ }^{4}$, and Andrea Figus, MD (Hons), PhD (Hons), FEBOPRAS ${ }^{5,6}$

${ }^{1}$ Leeds Teaching Hospitals Trust, Leeds, UK; ${ }^{2}$ University of Leeds, Leeds, UK; ${ }^{3}$ Norfolk and Norwich University Hospital, Norwich, UK; ${ }^{4}$ Great Ormond Street Hospital NHS Foundation Trust, London, UK; ${ }^{5}$ University Hospital, Cagliari, Italy; ${ }^{6}$ University of Cagliari, Cagliari, Italy

\section{CORRECTION TO: ANN SURG ONCOL}

HTTPS://DOI.ORG/10.1245/S10434-017-6173-Z

In the original article Justin C. R. Wormald's middle initials were incorrect. They are correct as reflected in this erratum. The original article has also been corrected.

The online version of the original article can be found under https:// doi.org/10.1245/s10434-017-6173-z.

(C) Society of Surgical Oncology 2017

Published Online: 20 November 2017

A. Figus, MD (Hons), PhD (Hons), FEBOPRAS e-mail: andreafigus@hotmail.com 